\section{Contextual cues in taste-aversion learning}

\author{
PER-OLOW SJÖDÉN \\ Uppsala University, Uppsala, Sweden \\ and \\ TREVOR ARCHER \\ Astra Läkemedel AB, Södertälje, Sweden
}

In this final statement concerning the role of contextual cues in taste-aversion learning, we would like to reiterate the three main points postulated by Holder (1988b) to be of critical issue in the exchange between him and ourselves. It is important not to ignore the fact that there may be several more essential points that should be considered in the analysis of taste-aversion learning and contextual variables (see Garcia, 1988).

Holder's (1988b) three main points are as follows:

1. "This confound has been empirically shown to be important and could explain their results" (p. 241). We would like to emphasize that the empirical foundation of Holder's argument on this point rests on two studies (Finch, 1985; Garcia, McGowan, \& Green, 1972), one of which is unpublished. There can be no doubt that Holder's interpretation of the results of these studies are instances of retrospective analyses. That is, none of the studies were explicitly designed to test the hypothesis that nozzle cues affect taste discriminations. As we have previously pointed out, the methodology of the Garcia et al. (1972) study leaves much to be desired. If, as stated by Holder (1988b, p. 240), the terms "spouts" and "tubes" employed by Garcia et al. (1972) to describe their procedure (p. 6) are supposed to refer to the same "spout and stopper" (Holder, 1988a, p. 240), this is completely unintelligible from their description. It is indeed fortunate that this piece of information is now made public property! Finally, if the results of Finch's (1985) unpublished dissertation are of the importance maintained by Holder, one eagerly awaits, with trepidation, their eventual publication.

We have performed four critical experiments, all explicitly designed to test Holder's argument, two of which were presented in our previous reply (Sjödén \& Archer, 1988a). The two remaining studies will be published in a forthcoming paper. The latter studies were designed to test the influence of tongue-tactile (nozzle) cues on the taste-preexposure effect in aversion learning in the absence of possible confounding taste cues from the fluid containers. The results provided strong evidence in favor of our position that the plastic-taste confound postulated

Reprints may be obtained from Per-Olow Sjödén, Department of Clinical Psychology, Uppsala University, Box 1225, S-75142 Uppsala, Sweden. by Holder (1988a, 1988b) cannot explain our extinction and latent inhibition effects. This should be contrasted with the fact that Holder's argument is based on retrospective analyses of a few studies, which used dubious methodology. Thus, so far, the weight of empirical evidence seems to rest with us.

2. "Sjödén and Archer [1988a] showed that they can replicate their results without this confound. Although they do not measure the effect of the confound separately, one can assume that their earlier work cannot be completely explained by the presence of this confound" (p. 241).

The implications of this assumption should be noted. It presupposes that any one of the effects demonstrated in our earlier work may be explained by the confound. Until discrete experiments are designed and performed to test this issue, it should be noted that there is no empirical evidence to show that any of the effects previously reported can be explained by the confound. We can but deplore the unnecessary exercise involved in the fencing match that Holder has dragged us into on this point.

3. "Assuming that their earlier work is not explained by the confound, we are left with essentially a replication and extension of earlier work showing that animals can learn associations between drinking spouts and illness... Sjödén and Archer have emphasized that their work is important and interesting because their results show that the context exerts strong control over the development of associations involving illness. However, tongue-tactile stimulation is uniquely correlated with taste, and therefore, like taste, should not be considered as a contextual stimulus" (Holder, 1988b, p. 241).

With his arguments on the topic of how to define contextual stimuli, Holder (1988b) has introduced an entirely new ball game, which can hardly be given fair treatment in an exchange of this nature. However, we have progressively, over the last decade, come to agree to a very great extent with the essential message conveyed here by Holder (cf. Sjödén \& Archer, 1988b). The main problem with Holder's definition of contextual cues is that it puts the entire field of context and learning into a conceptual straitjacket. Needless to say, such preoccupation may well leave this particular scientific enterprise in an impoverished state. Several explicit definitions of what constitutes context and contextual stimuli are extant in the unique volume edited by Balsam and Tomie (1985). For instance, Balsam (1985), in referring to functional aspects of context, states that "context has been invoked in circumstances where it 'disambiguates' $\ldots$ or gives an ambiguous stimulus meaning" (p. 2). Baker, Singh, and Bindra (1985) use the term contextual stimuli to encompass any stimulus other than the explicit CS or US. As indicated by Randich and Ross (1985) and ourselves (Archer, Sjödén, \& Nilsson, 1985), part of the issue discussed here owes its origin to the difficulty in experimentally defining, controlling, and measuring responses evoked by con- 
textual stimuli. Overton (1985) goes so far as to utilize internal stimulus states (state-dependent learning) as a contextual variable (see also Mackintosh, 1985). We have more explicitly expressed our position on this issue in the following manner (cf. Thomas, 1985): "The central concern in the study of contextual stimulus control is thus the effect of one stimulus on the control of behavior exercised by other stimuli (e.g. nominal CSs)" (Sjödén \& Archer, 1988b). To be more precise, we have attempted to define contextual stimuli as "exteroceptive stimuli within an experimental environment that are not purposely correlated with CS and US presentations" (Sjödén \& Archer, 1988b). Although this statement comes close to the position maintained by Holder (1988b), the term "purposely correlated" should be noted in particular. In the final analysis, these terms are defined from the experimenter's point of view, and the distinction between contextual stimuli and CSs/USs may be quite arbitrary from the learning organism's position. CSs/USs are frequently phasic and more novel to the organism than are contextual stimuli, but this is not an absolute distinction (cf. Archer et al., 1985, p. 226).

We suggest here that although conceptual stringency is to be sought after in the definition of contextual stimuli, it is important that this not occur at the expense of creative or innovative ideas. It may be that the field of context and learning is still at a stage of relative infancy, and that any stifling definition of central terms could well lead to a stunted growth of this fascinating topic.

Holder (1988a, 1988b) has illuminated the potential risks involved in the methodology of taste-aversion experiments. Interestingly, unrelated, but rather more controversial, issues were prevalent some 10 years ago in this field (e.g., Bitterman, 1976; Mitchell, 1977; Revusky, $1977,1978)$. For these efforts to correct possible artifacts, one can only acclaim Holder (1988a, 1988b). Of course, we have tried to argue and present experimental evidence against his position, but in the final analysis, we express gratitude for his having instigated experiments that should probably have been performed a long time ago.

\section{REFERENCES}

ARCHER, T., SJödÉN, P.-O., \& Nilsson, L. G. (1985). Contextual control of taste-aversion conditioning and extinction. In P. D. Balsam \& A. Tomie (Eds.), Context and learning (pp. 225-271). Hillsdale, NJ: Erlbaum.
BAKER, A. G., Singh, M., \& BindRA, D. (1985). Some effects of contextual conditioning and US predictability on Pavlovian conditioning. In P. D. Balsam \& A. Tomie (Eds.), Context and learning. (pp. 73103). Hillsdale, NJ: Erlbaum.

Balsam, P. D. (1985). The functions of context in learning and performance. In P. D. Balsam \& A. Tomie (Eds.), Context and learning. Hillsdale, NJ: Erlbaum.

Balsam, P. D., \& Tomie, A. (1985). Context and leaming. Hillsdale, NJ: Erlbaum.

Bitterman, M. E. (1976). Flavor aversion studies. Science, 192, 265-267.

FINCH, B. (1985). Effects of excitatory contexts on conditioned inhibition in taste aversion. Unpublished doctoral dissertation proposal, University of California at Los Angeles.

GARCIA, J. (1988). Food for Tolman: Cognition and cathexis in concert. In T. Archer \& L. G. Nilsson (Eds.), Aversion, avoidance and anxiety: Perspectives on aversively motivated behavior. Hillsdale, $\mathrm{NJ}$ : Erlbaum.

Garcia, J., McGowan, B. K., Green, K. F. (1972). Biological constraints on conditioning. In A. H. Black \& W. F. Prokasy (Eds.), Classical conditioning: II. Current research and theory (pp. 3-27). New York: Appleton-Century-Crofts.

Holder, M. D. (1988a). Possible role of confounded taste in conditioned taste aversions. Animal Learning \& Behavior, 16, 231-234.

HoLDER, M. D. (1988b). Reply to Sjödén and Archer. Animal Learning \& Behavior, 16, 240-241.

MaCkINTOSH, N. J. (1985). Contextual specificity or state dependency of human and animal learning. In L. G. Nilsson \& T. Archer (Eds.), Perspectives on learning and memory. Hillsdale, NJ: Erlbaum.

MITCHELl, D. (1977). Reply to Revusky. Animal Learning \& Behavior, $5,321-322$.

Overton, D. A. (1985). Contextual stimulus effects of drugs and internal states. In P. D. Balsam \& A. Tomie (Eds.), Context and learning (pp. 357-381). Hillsdale, NJ: Erlbaum.

Randich, A., Ross, R. T. (1985). Contextual stimuli mediate the effects of pre- and postexposure to the unconditioned stimulus on conditioned suppression. In P. D. Balsam \& A. Tomie (Eds.), Context and learning (pp. 105-132). Hillsdale, NJ: Erlbaum.

Revusky, S. (1977). Correction of a paper by Mitchell, Scott and Mitchell. Animal Learning \& Behavior, 5, 320.

Revusky, S. (1978). Reply to Mitchell. Animal Learning \& Behavior, 6, 119-120.

SJödÉN, P.-O., \& ARChER, T. (1988a). Exteroceptive cues in tasteaversion learning, no artifact: A reply to Holder. Animal Learning \& Behavior, 16, 235-239.

SjöDÉN, P.-O., \& ARCHER, T. (1988b). Taste-aversion conditioning: The role of contextual stimuli. In T. Archer \& L. G. Nilsson (Eds.), Aversion, avoidance and anxiety: Perspectives on aversively motivated behavior. Hillsdale, NJ: Erlbaum.

Thomas, D. R. (1985). Contextual stimulus control of operant responding in pigeons. In P. D. Balsam \& A. Tomie (Eds.), Context and learning (pp. 295-321). Hillsdale, NJ: Erlbaum.

(Manuscript accepted for publication March 7, 1988.) 